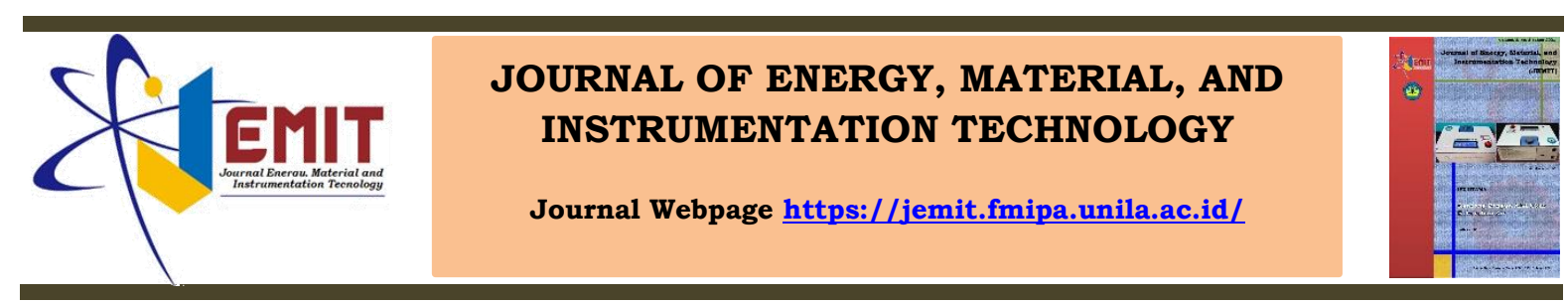

\title{
Rancang Bangun Alat Ukur Kekeruhan Air Menggunakan Fototransistor dan LED Inframerah Berbasis Arduino Uno
}

\author{
Nita Suliyani*, Sri Wahyu Suciyati, Gurum Ahmad Pauzi, dan Arif Surtono
}

Jurusan Fisika, Universitas Lampung, Bandar Lampung, Indonesia, 35141

\begin{tabular}{|c|c|}
\hline Article Information & Abstract \\
\hline $\begin{array}{l}\text { Article history: } \\
\text { Received April 1st, } 2021 \\
\text { Received in revised form } \\
\text { April 20th, } 2021 \\
\text { Accepted May 5th, } 2021\end{array}$ & 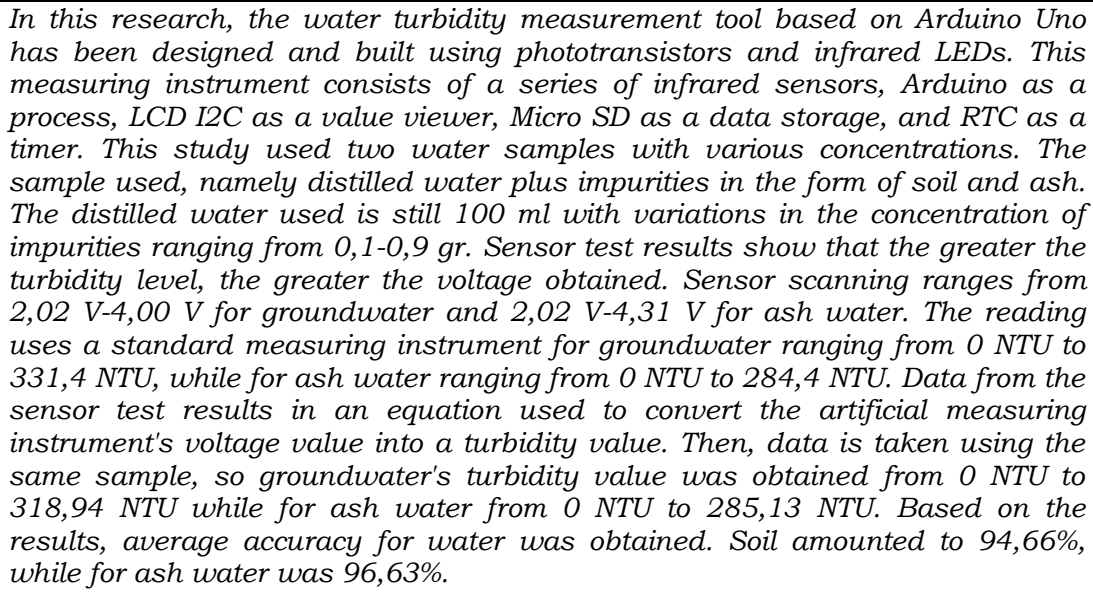 \\
\hline Informasi Artikel & Abstrak \\
\hline $\begin{array}{l}\text { Proses artikel: } \\
\text { Diterima 1 April } 2021 \\
\text { Diterima dan direvisi dari } \\
20 \text { April } 2021 \\
\text { Accepted } 5 \text { Mei } 2021\end{array}$ & $\begin{array}{l}\text { Pada penelitian ini, telah dirancang dan dibuat alat ukur kekeruhan air } \\
\text { berbasis Arduino Uno dengan menggunakan Fototransistor dan LED } \\
\text { inframerah. Alat ukur ini terdiri dari rangkaian sensor inframerah, Arduino } \\
\text { sebagai proses, LCD I2C sebagai penampil nilai, Micro SD sebagai penyimpan } \\
\text { data dan RTC sebagai pengatur waktu. Penelitian ini menggunakan dua } \\
\text { sampel air dengan variasi konsentrasi. Sampel yang digunakan, yaitu aquades } \\
\text { ditambah zat pengotor berupa tanah dan abu. Jumlah aquades yang } \\
\text { digunakan tetap yaitu } 100 \text { ml dengan variasi konsentrasi zat pengotor mulai } \\
\text { dari } 0,1-0,9 \text { gr. Hasil pengujian sensor menunjukkan bahwa semakin besar } \\
\text { tingkat kekeruhan, maka semakin besar pula tegangan yang diperoleh. } \\
\text { Pembacaan uji sensor pada alat buatan mulai dari } 2,02 \mathrm{~V} \text { hingga } 4,00 \mathrm{~V} \text { untuk } \\
\text { air tanah dan } 2,02 \mathrm{~V} \text { hingga } 4,31 \mathrm{~V} \text { untuk air abu. Pembacaan menggunakan } \\
\text { alat ukur standar untuk air tanah mulai dari O NTU hingga } 331,4 \text { NTU, } \\
\text { sedangkan untuk air abu mulai dari O NTU hingga } 284,4 \text { NTU. Data hasil } \\
\text { pengujian sensor menghasilkan persamaan yang digunakan untuk mengubah } \\
\text { nilai tegangan alat ukur buatan menjadi nilai kekeruhan. Kemudian, dilakukan } \\
\text { pengambilan data menggunakan sampel yang sama sehingga diperoleh nilai } \\
\text { kekeruhan untuk air tanah mulai dari O NTU hingga 318,94 NTU sedangkan } \\
\text { untuk air abu mulai dari O NTU hingga } 285,13 \text { NTU.Berdasarkan hasil yang } \\
\text { diperoleh rata- rata akurasi untuk air tanah sebesar } 94,66 \% \text {, sedangkan untuk } \\
\text { air abu sebesar } 96,63 \% \text {. }\end{array}$ \\
\hline
\end{tabular}

\section{Pendahuluan}

Air memiliki peran penting dalam kehidupan manusia, sebagian besar kegiatan yang dilakukan manusia membutuhkan air, mulai dari membersihkan diri (mandi), membersihkan ruangan tempat tinggalnya, menyiapkan makanan dan minuman, dan berbagai keperluan sanitasi lainnya, seperti mencuci tangan, baju dan peralatan rumah tangga (Rukaesih, 2004). Hal ini menjadi alasan agar kita memperhatikan kelayakan air yang digunakan. Air yang bersih memiliki beberapa parameter fisika dan kimia yang harus terpenuhi, salah satunya yaitu tingkat 
kekeruhan (turbidity) (Silalahi, 2010). Tingkat kekeruhan pada air dapat menimbulkan kekhawatiran bahwa di dalam air yang digunakan terdapat bahan-bahan yang membahayakan tubuh manusia dan menyebabkan terkena penyakit (Sutrisno, 2004). Kekeruhan merupakan sifat optik dari suatu larutan yang menyebabkan cahaya yang melaluinya terabsorbsi dan terbias (Kadir, 2013). Kekeruhan dinyatakan dalam satuan NTU (Nephelometric Turbidity Units) dan diukur menggunakan alat ukur standar, yaitu turbidimeter (Joko, 2010). Namun, alat ini hanya dimiliki oleh pihak-pihak tertentu, sehingga pengembangan berbagai alat ukur kekeruhan air dilakukan dengan memanfaatkan rangkaian elektronika.

Yusfi et al. (2011) melakukan penelitian mengenai alat pendeteksi kekeruhan air dengan menggunakan fototransistor dan LED inframerah sebagai input. Namun, hasil keluaran pada alat ini masih dalam bentuk alarm. Hendrizon \& Wildian (2012) menghasilkan alat ukur tingkat kekeruhan zat cair menggunakan sensor yang sama, mikrokontroler AT89S51 sebagai proses, dan keluaran berupa LCD. Pada alat ini posisi fototransistor $90^{\circ}$ terhadap cahaya yang datang dari LED. Alat ini mampu mengukur dalam rentang $6-164$ NTU. Nuzula \& Endarko (2013) membuat alat ukur kekeruhan air menggunakan sensor fotodioda dan LED yang diposisikan sejajar, dan LCD sebagai outputnya. Alat ini mampu mengukur kekeruhan dengan rentang 0 - 200 NTU. Kautsar et al. (2015) membuat sistem monitoring kekeruhan air dengan sensor yang sama namun menggunakan mikrokontroller ATMega 328 sebagai proses. Alat ini memiliki batas pengukuran hingga 173 NTU dengan akurasi pengukuran $98,8 \%$.

Faisal et al. (2016), merancang sistem monitoring kekeruhan air dengan sensor TSD-10 sebagai input dan mikrokontroller ATMega 8 sebagai proses. Namun hasilnya dapat ditampilkan jika terhubung dengan komputer. Pada tahun yang sama, Maemunnur et al. (2016), juga membuat alat ukur turbidity menggunakan sistem sensor yang terdiri dari dioda laser dan fotodioda TSL250. Alat ukur yang dibuat mempunyai tingkat akurasi pengukuran 98,70\%. Namun, tidak memiliki penyimpanan data. Zamri (2017), melakukan penelitian dengan membuat alat pendeteksi kekeruhan air menggunakan LDR dan Arduino Uno sebagai proses, serta LCD sebagai output. Rentang pengukuran alat ini mulai dari $0-130,6$ NTU. Namun, sensor yang digunakan kurang peka dan sumber cahayanya masih terpengaruh oleh sinar ultraviolet. Kemudian Ikhsan et al. (2018), membuat pendeteksi kekeruhan air dengan sensor yang sama namun output yang dihasilkan berupa LED berwarna hijau, kuning dan merah sebagai indikasi kekeruhan, sehingga tidak dapat diketahui hasil pengukurannya.

Pada penelitian ini, dibuat alat ukur kekeruhan air menggunakan sensor inframerah, dengan transmitter berupa LED Inframerah dan receiver berupa fototransistor. Penggunaan fototransistor sebagai receiver, karena arus yang dibangkitkan lebih besar sehingga fototransistor lebih sensitif dibandingkan dengan fotodioda (Fraden, 2003). Pada sistem pengukuran ini digunakan mikrokontroler ATMega 328P dengan papan sirkuit Arduino Uno. Sebagai keluaran, nilai kekeruhan akan ditampilkan pada LCD dan disimpan pada Micro SD.

\section{Metode Penelitian}

Alat yang digunakan dalam penelitian ini adalah multimeter digital, gelas ukur, neraca digital, turbidymeter $Q A D-01$, solder, kawat timah dan bor. Bahan yang digunakan dalam penelitian ini adalah Arduino Uno, LCD I2C, Resistor, adapter, fototransistor, LED inframerah, tabung sampel, RTC DS3231, Micro SD, push button, kotak hitam, aquades, tanah dan abu.

\subsection{Perancangan Sensor Inframerah}

Perancangan rangkaian sensor inframerah, terdiri dari fototransistor, LED inframerah, trimpot 10k, resistor $10 \mathrm{k}$ dan $220 \Omega$. Pada rangkaian ini fototransistor dan LED inframerah dipasang berhadapan dengan jarak $3 \mathrm{~cm}$. Jarak tersebut disesuaikan dengan ukuran tabung sampel yang akan diletakkan diantara keduanya. Rangkaian sensor inframerah ditunjukkan pada Gambar 1.

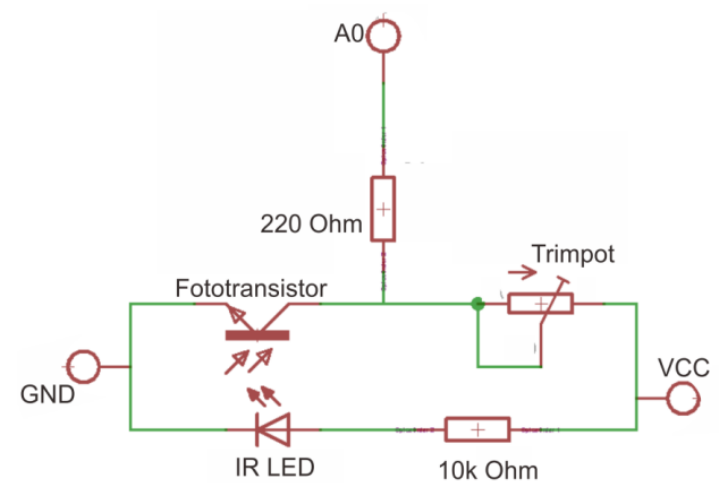

Gambar 1. Rangkaian sensor inframerah

Pada dasarnya sistem ini menggunakan inframerah sebagai media komunikasi data antara receiver dan transmitter. Sistem akan bekerja jika sinar inframerah yang dipancarkan terhalang oleh suatu benda sehingga sinar tidak dapat terdeteksi oleh penerima (Artanto, 2012). Prinsipnya, cahaya yang dikeluarkan oleh LED akan ditangkap oleh fototransistor sehingga menghasilkan tingkat emisi cahaya yang berbeda jika di air bersih dan air keruh. Pada air yang keruh terdapat bahan anorganik atau organik yang bisa mengabsorsi emisi cahaya LED sehingga intensitas cahaya menjadi berkurang. Hal ini menyebabkan tegangan yang dibaca oleh fototransistor menjadi berbeda antara air bersih dan air keruh (Yusfi et al., 2011). 
Suliyani N, Suciyati SW, Pauzi GA, dan Surtono A, 2021, Rancang Bangun Alat Ukur Kekeruhan Air Menggunakan Fototransistor dan LED Inframerah Berbasis Arduino Uno, Journal of Energy, Material, and Instrumentation Technology, Vol. 2 No. 2, 2021

\subsection{Rancangan Keseluruhan Alat}

Rancangan alat ukur kekeruhan ini terdiri dari sensor inframerah sebagai rangkaian input, Arduino Uno sebagai proses, Micro SD sebagai penyimpan data, RTC DS3231 sebagai pengatur waktu dan LCD sebagai output. Blok diagram rancangan ini ditunjukkan pada Gambar 2.

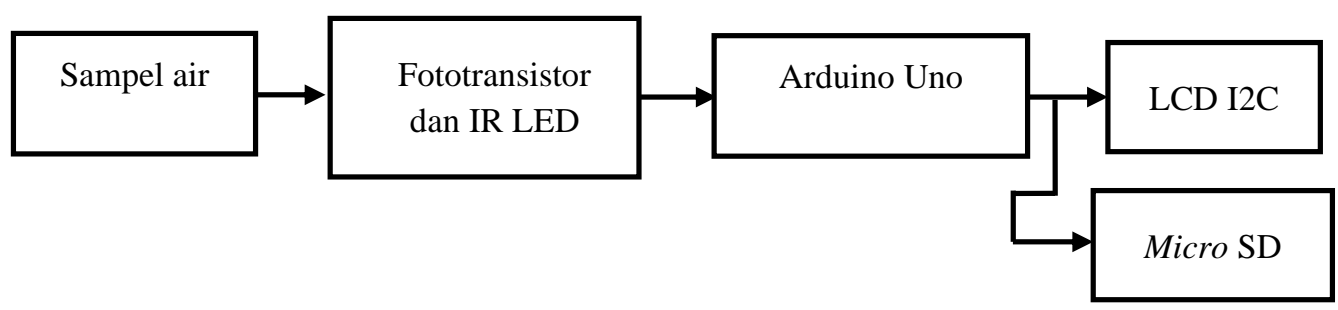

Gambar 2. Diagram blok

Prinsip kerja alat ukur kekeruhan sebagai berikut:

Sampel air akan diletakkan diantara LED inframerah dan fototransistor, LED inframerah memancarkan cahaya yang akan diterima fototransistor. Intensitas cahaya inilah yang kemudian dibaca oleh fototransistor. Masukan (input) dari pembacaan sensor fototransistor akan diterima oleh Arduino. Nilai analog yang dihasilkan sensor akan dibaca dan diproses oleh Arduino, sehingga menghasilkan nilai tegangan. Kemudian, nilai tegangan akan dinyatakan sebagai nilai kekeruhan air dalam bentuk NTU (Nephelometric Turbidity Unit). Nilai kekeruhan air akan ditampilkan pada LCD dan data akan disimpan dalam Micro SD. Rangkaian alat secara keseluruhan ditunjukkan pada Gambar 3.

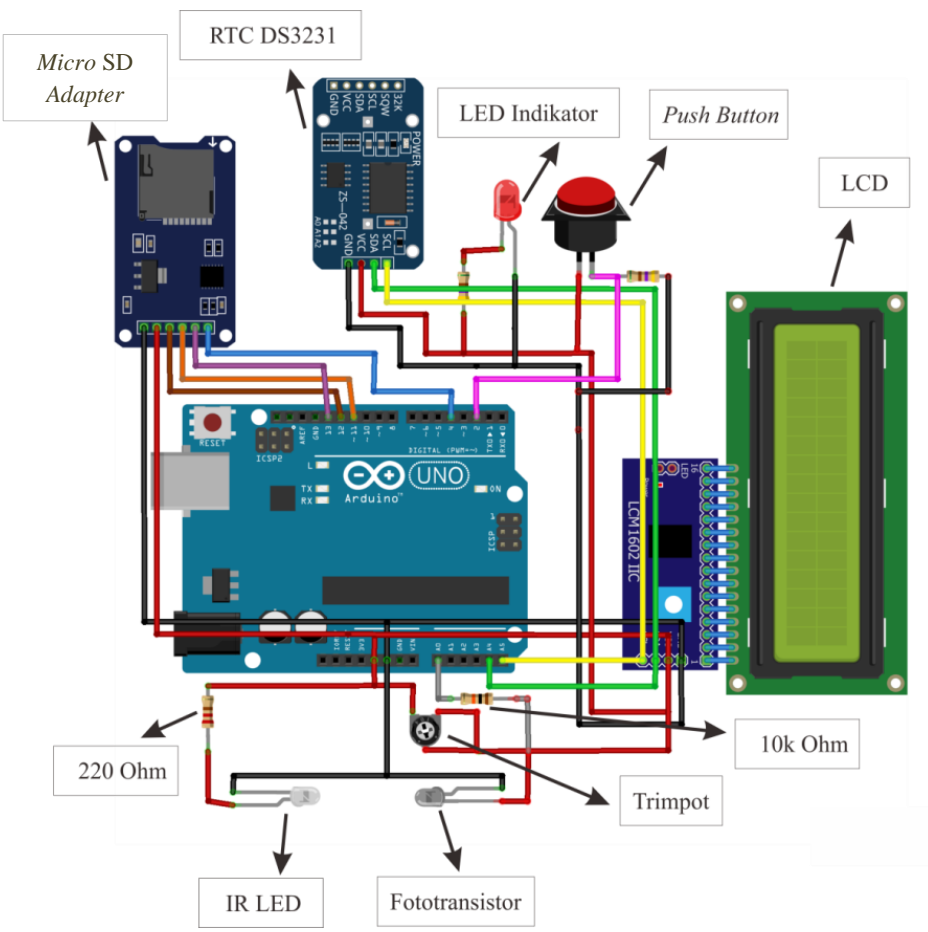

Gambar 3. Rangkaian keseluruhan alat

Pada penelitian ini digunakan dua jenis sampel dengan variasi konsentrasi yang terkandung dalam air. Sampel ini menggunakan aquades $100 \mathrm{ml}$ dengan tambahan zat pengotor, berupa tanah dan abu. Setiap zat pengotor dibuat 10 sampel dengan variasi konsentrasi mulai dari 0,1 - 0,9 gr.

\section{Hasil Dan Pembahasan}

\subsection{Realisasi Alat}

Alat ukur kekeruhan untuk mengetahui nilai kekeruhan air telah direalisasikan dengan menggunakan sensor inframerah yang terdiri dari fototransistor dan led inframerah. Phototransistor bekerja sebagai receiver, sedangkan led inframerah sebagai transmitter. Nilai kekeruhan ditampilkan menggunakan LCD beresolusi 16x2 karakter, penyimpanan data hasil rekam otomatis menggunakan Micro SD yang dilakukan secara real time menggunakan RTC DS3231 berbasis Arduino Uno R3. Wadah alat dibuat dari bahan plastik berwarna hitam 
dengan ukuran $18 \mathrm{~cm} \times 11 \mathrm{~cm} \times 6 \mathrm{~cm}$. Realisasi alat ukur kekeruhan air bagian luar dapat dilihat pada Gambar 4.

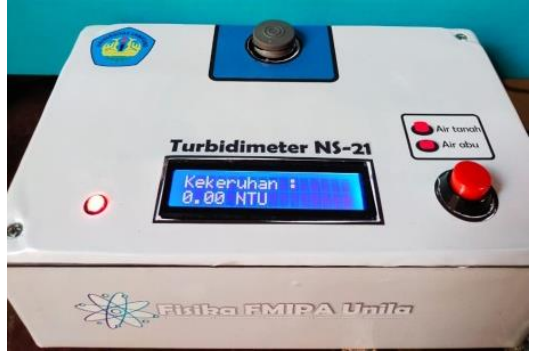

(a)

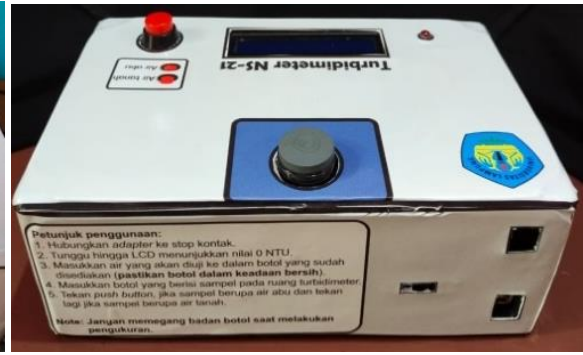

(b)

Gambar 4. Realisasi rancangan alat bagian luar, (a) tampak depan, (b) tampak belakang

Gambar 4. (a) menunjukkan realisasi alat bagian luar tampak depan. Pada sisi atas terdapat lubang yang di dalamnya telah dipasang sensor inframerah yang terdiri dari LED inframerah dan fototransistor. Keduanya diletakkan berhadapan agar intensitas cahaya dari LED inframerah dapat langsung dideteksi oleh fototransistor. Lubang ini sebagai tempat untuk meletakkan botol sampel yang diisi air keruh. Selain itu, di sisi atas juga terdapat LCD sebagai penampil informasi berupa tegangan dan nilai kekeruhan, LED indikator dan push button. Hasil karakteristik sensor menghasilkan dua persamaan, yaitu persamaan dari sampel air abu dan air tanah, sehingga kedua persamaan dimasukkan ke dalam program. Namun, nilai yang ditampilkan hanya salah satunya saja, sehingga digunakan push button untuk memilih nilai yang ditampilkan sesuai air yang diukur. Gambar 4. (b) menunjukkan sisi belakang alat ukur buatan. Pada bagian belakang terdapat tempat untuk micro SD, lubang untuk adaptor $9 \mathrm{~V}$ dan USB Arduino, serta petunjuk penggunaan alat.

\subsection{Realisasi Rangkaian}

Alat ukur kekeruhan air, terdiri dari beberapa rangkaian yang dihubungkan ke Arduino Uno, diantaranya yaitu rangkaian Micro SD, rangkaian LCD I2C, rangkaian RTC DS3231, dan rangkaian sensor inframerah.

\section{Rangkaian Micro SD}

Micro SD Adapter digunakan untuk membaca Micro SD Card menggunakan Arduino. Micro SD digunakan sebagai media penyimpanan data dari hasil pengukuran. Kapasitas Micro SD yang digunakan sebesar 4 GB. Modul micro SD card adapter menggunakan 6 pin untuk berkomunikasi dengan Arduino, diantaranya MOSI, MISO, SCK, CS dan pin power, yakni VCC dan GND (Ebaay Search, 2013). Jalur MISO dihubungkan dengan pin 12 Arduino, jalur SK dihubungkan dengan pin 13 Arduino, jalur CS dihubungkan dengan pin 4 Arduino, dan MOSI dihubungkan dengan pin 11 Arduino.

\section{Rangkaian LCD I2C}

LCD merupakan output dalam sistem mikrokontroler yang dapat menampilkan teks yang terdiri dari berbagai karakter dan angka (Mazidi, 2011). Penggunaan LCD dan driver IC PCF8574T untuk berkomunikasi dengan Arduino Uno membutuhkan 4 pin yakni VCC, GND, SCL, dan SDA (Mantech Electronics, 2017). LCD I2C berkomunikasi menggunakan pin SDA dan SCL yang dihubungkan ke pin A4 dan A5 Arduino. Kemudian untuk VCC dihubungkan ke pin $5 \mathrm{~V}$ pada Arduino.

\section{Rangkaian RTC DS3231}

DS3231 digunakan sebagai pengatur waktu yang meliputi detik, menit, jam, hari, tanggal, bulan dan tahun (Khoswanto, 2003). RTC DS3231 berkomunikasi dengan dua jalur yaitu SCL dan SDA. Untuk komunikasi SCL dihubungkan dengan pin A5 Arduino sedangkan SDA dihubungkan dengan pin A4 Arduino.

\section{Rangkaian sensor inframerah}

Komponen utama rangkaian ini, yaitu LED inframerah dan fototransistor. Fototransistor yang digunakan terdiri dari dua kaki, yaitu kaki kolektor dan emitor. Sedangkan, basis transistor mendapat masukan berupa cahaya yang dipancarkan oleh LED, dan kolektor sebagai keluaran tegangan dari rangkaian. Output dari sensor dihubungkan ke pin AO pada Arduino Uno.

\subsection{Pengambilan Data Jarak}

Pengambilan data jarak transmitter-receiver dilakukan dengan membandingkan tegangan yang diperoleh pada setiap jarak. Pengambilan data ini bertujuan untuk memperoleh jarak optimal transmitterreceiver yang akan diaplikasikan pada tabung sampel. Pengukuran dilakukan dengan mengukur tegangan output rangkaian dengan penghalang dan tanpa penghalang dengan jarak yang berbeda-beda antara LED inframerah dan fototransistor. Nilai tegangan yang diperoleh pada setiap jarak dapat dilihat pada Tabel 1. 
Suliyani N, Suciyati SW, Pauzi GA, dan Surtono A, 2021, Rancang Bangun Alat Ukur Kekeruhan Air Menggunakan Fototransistor dan LED Inframerah Berbasis Arduino Uno, Journal of Energy, Material, and Instrumentation Technology, Vol. 2 No. 2, 2021

Tabel 1. Data pengukuran tegangan transmitter-receiver

\begin{tabular}{ccc}
\hline Jarak $(\mathrm{cm})$ & Tegangan tanpa penghalang $(\mathrm{V})$ & Tegangan dengan penghalang $(\mathrm{V})$ \\
\hline 2 & 0,1 & 4,95 \\
3 & 0,11 & 4,96 \\
4 & 0,12 & 4,95 \\
5 & 0,14 & 4,94 \\
6 & 0,15 & 4,94 \\
7 & 0,15 & 4,95 \\
\hline
\end{tabular}

Berdasarkan hasil pengukuran tegangan pada Tabel 1 dapat disimpulkan bahwa nilai tegangan tanpa penghalang merupakan nilai tegangan minimum dan nilai tegangan dengan penghalang merupakan nilai maksimum. Pengukuran dimulai dari jarak 2 hingga $7 \mathrm{~cm}$, dari tabel terlihat bahwa semakin besar jarak antara LED inframerah dan fototransistor, maka semakin besar pula nilai tegangan minimum yang diperoleh. Pada penelitian ini sensor diberi jarak $3 \mathrm{~cm}$, agar tidak terlalu dekat dan dapat memuat botol sampel yang berukuran $2,5 \mathrm{~cm}$.

\subsection{Karakteristik Sensor dan Kalibrasi}

Pada pengambilan data karakteristik sensor dibuat dua buah sampel, dimana masing-masing sampel terdiri dari 10 variasi konsentrasi zat pengotor. Sebelum dilakukan pengambilan data, terlebih dahulu dilakukan pengukuran tegangan tanpa botol sampel, dengan botol sampel dalam kondisi kosong dan kondisi botol berisi air yang sedikit keruh. Namun dari hasil pengujian tidak terjadi perubahan tegangan pada ketiga kondisi tersebut. Hal ini dikarenakan intensitas cahaya dari LED inframerah yang terlalu besar sehingga perubahan kondisi tidak terdeteksi oleh fototransistor. Maka, intensitas cahaya dikurangi agar perubahan pada air dapat terdeteksi oleh fototransistor, sehingga nilai tegangan minimum diatur pada 1,94 V. Nilai minimum ini merupakan kondisi saat tidak ada botol sampel diantara LED inframerah dan fototransistor.

Pengambilan data dilakukan dengan membandingkan tingkat kekeruhan dengan nilai tegangan yang diperoleh dari pengukuran menggunakan alat ukur yang dibuat. Kemudian dilakukan perbandingan nilai tegangan dengan nilai kekeruhan yang diukur menggunakan alat ukur standar untuk memperoleh persamaan kalibrasi. Alat ukur standar yang digunakan pada penelitian ini, yaitu Turbidymeter tipe TBD-QAD-01. Hasil pengukuran dapat dilihat pada Tabel 2.

Tabel 2. Data kalibrasi air tanah

\begin{tabular}{clcc}
\hline No & Jenis Sampel & Tegangan (V) & Kekeruhan (NTU) \\
\hline 1 & Aquades Murni & 2,02 & 0 \\
2 & Aquades + tanah 0,1 gr & 2,16 & 60,4 \\
3 & Aquades + tanah 0,2 gr & 2,26 & 122,4 \\
4 & Aquades + tanah 0,3 gr & 2,33 & 131,4 \\
5 & Aquades + tanah 0,4 gr & 2,55 & 146,3 \\
6 & Aquades + tanah 0,5 gr & 2,71 & 182,5 \\
7 & Aquades + tanah 0,6 gr & 3,08 & 220,9 \\
8 & Aquades + tanah 0,7 gr & 3,21 & 263 \\
9 & Aquades + tanah 0,8 gr & 3,89 & 296,1 \\
10 & Aquades + tanah 0,9 gr & 4,00 & 331,4 \\
\hline
\end{tabular}

Berdasarkan data pada Tabel 2, maka diperoleh grafik karakteristik sensor dengan menggunakan sampel air tanah ditunjukkan pada Gambar $\mathbf{5}$.

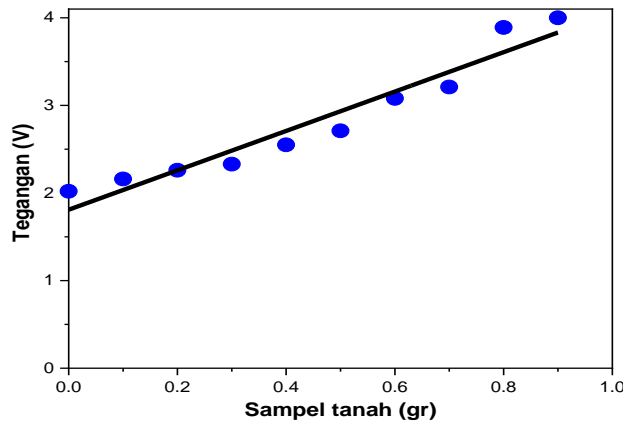

Gambar 5. Grafik karakteristik sensor dengan air tanah 
Gambar 4.13 menunjukkan grafik karakteristik sensor yang merupakan perbandingan tingkat kekeruhan dengan nilai tegangan. Titik biru pada grafik menunjukkan nilai karakteristik sensor, sedangkan garis hitam menunjukkan trend regresi linier. Berdasarkan grafik terlihat bahwa semakin besar tingkat kekeruhan air tanah, maka semakin besar nilai tegangan yang diperoleh pada alat ukur buatan. Grafik perbandingan alat ukur buatan dan alat ukur standar untuk memperoleh persamaan kalibrasi ditunjukkan pada Gambar 6.

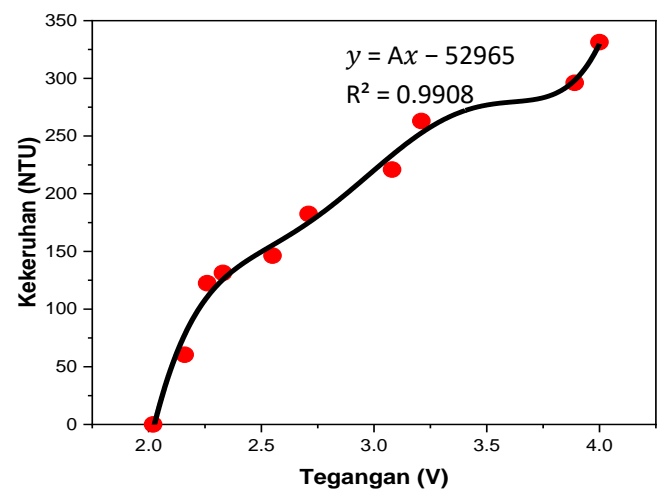

Gambar 6. Grafik kalibrasi tegangan dengan kekeruhan (air tanah)

Pada Gambar 6 diperoleh grafik perbandingan pengukuran alat ukur buatan dan alat ukur standar. Grafik ini digunakan untuk mengkalibrasi alat buatan dengan alat standar. Pada alat ukur buatan diperoleh nilai tegangan, pada alat ukur standar diperoleh hasil pengukuran berupa nilai kekeruhan dalam satuan NTU. Dari grafik terlihat bahwa semakin besar nilai tegangan, maka semakin besar pula nilai kekeruhan dari alat ukur standar. Grafik warna merah menunjukkan nilai perbandingan, sedangkan grafik warna hitam menunjukkan trend regresi linier dalam bentuk polinomial. Persamaan yang diperoleh dapat dilihat pada Persamaan 1.

$$
y=A x-52965
$$

Pada Persamaan 1 diketahui $\mathrm{A}=\left(223,33 x^{4}-3400,1 x^{3}+20487 x^{2}-61094 x+90339\right)$, dimana $\mathrm{x}$ adalah nilai tegangan yang diperoleh dari pembacaan alat ukur buatan, sedangkan y adalah nilai kekeruhan yang diukur menggunakan alat ukur standar. Lebih tepatnya persamaan ini digunakan untuk merubah nilai tegangan dari aat ukur buatan menjadi nilai kekeruhan dengan satuan NTU. Nilai $R^{2}=0,9908$ merupakan nilai ralat dengan maksud kesalahan ralat sebesar 0,9908 . Kemudian pengambilan data kedua dilakukan pada air abu, hasil pengukuran dapat dilihat pada Tabel 3.

Tabel 3. Data kalibrasi air abu

\begin{tabular}{clcc}
\hline No & Jenis Sampel & Tegangan (V) & Kekeruhan (NTU) \\
\hline 1 & Aquades Murni & 2,02 & 0 \\
2 & Aquades + abu 0, 1 gr & 2,11 & 26,4 \\
3 & Aquades + abu 0,2 gr & 2,21 & 71,94 \\
4 & Aquades + abu 0,3 gr & 2,35 & 106 \\
5 & Aquades + abu 0,4 gr & 2,48 & 130,7 \\
6 & Aquades + abu 0,5 gr & 2,9 & 175,7 \\
7 & Aquades + abu 0,6 gr & 3,26 & 216 \\
8 & Aquades + abu 0,7 gr & 3,69 & 235,2 \\
9 & Aquades + abu 0,8 gr & 3,89 & 267,6 \\
10 & Aquades + abu 0,9 gr & 4,31 & 284,4 \\
\hline
\end{tabular}

Berdasarkan data tingkat kekeruhan dan tegangan diperoleh grafik karakteristik sensor dengan sampel air abu yang ditunjukkan pada Gambar 7.

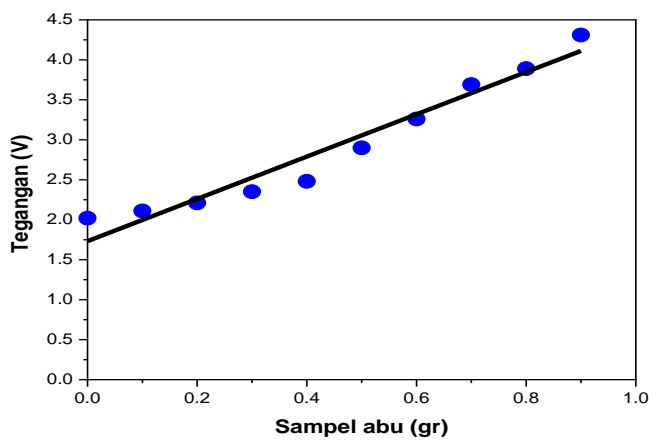

Gambar 7. Grafik karakteristik sensor dengan air abu 
Suliyani N, Suciyati SW, Pauzi GA, dan Surtono A, 2021, Rancang Bangun Alat Ukur Kekeruhan Air Menggunakan Fototransistor dan LED Inframerah Berbasis Arduino Uno, Journal of Energy, Material, and Instrumentation Technology, Vol. 2 No. 2, 2021

Gambar 7 menunjukkan grafik karakteristik sensor menggunakan sampel air abu yang merupakan perbandingan tingkat kekeruhan dengan nilai tegangan. Titik biru pada grafik menunjukkan nilai karakteristik sensor, sedangkan garis hitam menunjukkan trend regresi linier. Berdasarkan grafik terlihat bahwa semakin besar tingkat kekeruhan air abu, maka semakin besar pula nilai tegangan yang diperoleh pada alat ukur buatan. Setelah dilakukan karakteristik sensor, selanjutnya dilakukan pengukuran nilai kekeruhan dengan alat ukur standar. Kemudian nilai tegangan alat ukur buatan dibandingkan dengan nilai kekeruhan untuk memperoleh persamaan kalibrasi, sehingga diperoleh grafik yang ditunjukkan pada Gambar 8.

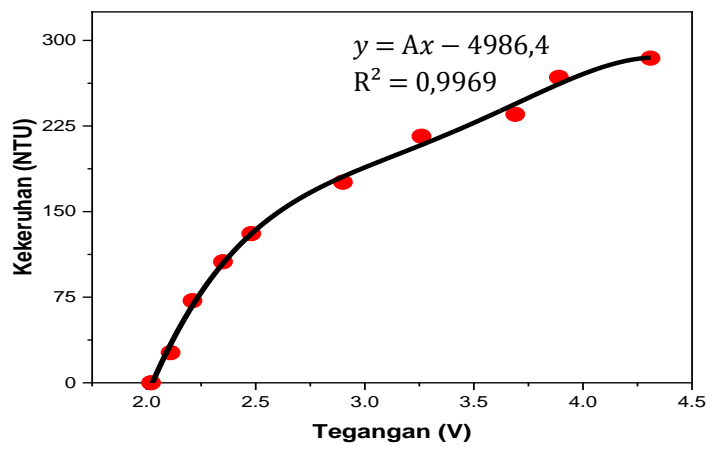

Gambar 8. Grafik kalibrasi tegangan dengan kekeruhan (air abu)

Gambar 8 menunjukkan perbandingan pengukuran dengan alat ukur buatan dan alat ukur standar. Grafik ini digunakan untuk mengkalibrasi alat buatan dengan alat standar. Pada alat ukur buatan diperoleh nilai tegangan, pada alat ukur standar diperoleh hasil pengukuran berupa nilai kekeruhan dalam satuan NTU. Dari grafik terlihat bahwa semakin besar nilai tegangan, maka semakin besar pula nilai kekeruhan dari alat ukur standar. Grafik warna merah menunjukkan nilai perbandingan, sedangkan grafik warna hitam menunjukkan grafik regresi linier dalam bentuk polinomial. Persamaan yang diperoleh dapat dilihat pada Persamaan 2.

$$
y=A x-4986,4
$$

Pada Persamaan 2 diketahui $A=\left(-37,493 x^{3}+513,12 x^{2}-2615,4 x+5965,5\right)$, dimana $\mathrm{x}$ adalah nilai tegangan yang diperoleh dari pembacaan alat ukur buatan, sedangkan y adalah nilai kekeruhan yang diperoleh dari hasil pengukuran menggunakan alat ukur standar. Nilai $R^{2}=0,9969$ merupakan nilai ralat dengan maksud kesalahan ralat sebesar 0,9969. Setelah dilakukan kalibrasi dan diperoleh persamaan untuk air abu dan air tanah, selanjutnnya kedua persamaan, yaitu Persamaan 1 dan 2 dimasukkan ke dalam program, sehingga program akan menghitung nilai kekeruhan untuk kedua air tersebut. Pada pengujian sensor diperoleh tegangan saat botol kosong sebesar 2,03 V, maka pada program jika voltage lebih kecil dari atau sama dengan 2,03 V dibuat sebanding dengan 0 NTU.

Berdasarkan hasil pengukuran pada kedua sampel diperoleh nilai tegangan minimum pada pengukuran aquades murni sebesar 2,02 V, sedangkan nilai minimum pada saat tidak ada botol sampel sebesar 1,94 V. Hal ini berkaitan dengan daya serap cahaya yang melalui suatu cairan dan wadahnya yang dikemukakan oleh Lambert dan Beer. Apabila seberkas cahaya melewati suatu larutan yang konsentrasinya c maka cahaya tersebut akan diserap dan sebagian akan diteruskan (Rohman, 2007). Wadah sampel dan cairan inilah yang menyebabkan kenaikan tegangan terjadi meskipun cairan tersebut transparan.

Fototransistor pada penelitian ini sangat sensitif terhadap cahaya. Kepekaan sensor ini terhadap cahaya membuat sensor ini terganggu pengukurannya jika sedikit saja terkena cahaya. Hal ini terbukti saat akan dilakukan pengambilan data tegangan dengan sampel botol kosong dan berisi air dengan tingkat kekeruhan berbeda sebelum intensitas cahaya dikurangi. Pada pengukuran tersebut tidak terjadi perubahan karena fototransistor yang sangat peka terhadap cahaya dari LED inframerah, sehingga intensitas cahaya harus dikurangi agar fototransistor dapat mendeteksi tingkat kekeruhan air.

\subsection{Pengambilan Data Akurasi dan Kesalahan}

Pada tampilan LCD yang ditampilkan hanya nilai kekeruhan dari salah satu persamaan. Pemilihan nilai kekeruhan yang akan ditampilkan dilakukan dengan menekan push button. Jika push button dalam keadaan LOW maka nilai yang akan ditampilkan adalah nilai kekeruhan untuk sampel berupa air dengan pengotor tanah. Namun, jika push button dalam keadaan HIGH maka nilai yang akan ditampilkan adalah nilai kekeruhan untuk sampel berupa air dengan pengotor abu. Setelah program selesai di-upload, maka dilakukan pengukuran menggunakan alat ukur buatan dengan pengulangan sebanyak 3 kali pada setiap sampelnya. Pengukuran dilakukan untuk mengetahui persentase akurasi dan kesalahan dari alat ukur yang dibuat. Hasil pengambilan data kekeruhan air tanah dengan alat ukur buatan dapat dilihat pada Tabel 4. 
Tabel 4. Data pengukuran alat ukur buatan (air tanah)

\begin{tabular}{clcccccc}
\hline No & \multicolumn{1}{c}{$\begin{array}{c}\text { Jenis } \\
\text { Sampel }\end{array}$} & $\begin{array}{c}\text { Pengukuran 1 } \\
\text { (NTU) }\end{array}$ & $\begin{array}{c}\text { Alat ukur buatan } \\
\text { Penukuran 2 } \\
\text { (NTU) }\end{array}$ & $\begin{array}{c}\text { Pengukuran 3 } \\
\text { (NTU) }\end{array}$ & $\begin{array}{c}\text { Alat } \\
\text { standar } \\
\text { (NTU) }\end{array}$ & $\begin{array}{c}\text { Akurasi } \\
\text { (\%) }\end{array}$ & $\begin{array}{c}\text { Kesalahan } \\
\text { (\%) }\end{array}$ \\
\hline 1 & $\begin{array}{l}\text { Aquades } \\
\text { Murni }\end{array}$ & 0 & 0 & 0 & 0 & 100 & 0 \\
2 & $\begin{array}{l}\text { Aquades + } \\
\text { tanah 0,1 gr }\end{array}$ & 67,7 & 67,7 & 72,13 & 60,4 & 85,47 & 14,53 \\
3 & $\begin{array}{l}\text { Aquades + } \\
\text { tanah 0,2 gr }\end{array}$ & 111,27 & 111,27 & 111,27 & 122,4 & 90,91 & 9,09 \\
4 & $\begin{array}{l}\text { Aquades + } \\
\text { tanah 0,3 gr }\end{array}$ & 123,8 & 123,8 & 123,8 & 131,4 & 94,22 & 5,78 \\
5 & $\begin{array}{l}\text { Aquades + } \\
\text { tanah 0,4 gr }\end{array}$ & 152,78 & 152,78 & 152,78 & 146,3 & 95,57 & 4,43 \\
6 & $\begin{array}{l}\text { Aquades + } \\
\text { tanah 0,5 gr }\end{array}$ & 175,52 & 175,52 & 175,52 & 182,5 & 96,18 & 3,82 \\
7 & $\begin{array}{l}\text { Aquades + } \\
\text { tanah 0,6 gr }\end{array}$ & 229,47 & 229,47 & 229,47 & 220,9 & 96,12 & 3,88 \\
8 & $\begin{array}{l}\text { Aquades + } \\
\text { tanah 0,7 gr }\end{array}$ & 247,69 & 249,09 & 249,09 & 263 & 94,53 & 5,47 \\
9 & $\begin{array}{l}\text { Aquades + } \\
\text { tanah 0,8 gr }\end{array}$ & 288,22 & 288,22 & 288,22 & 296,1 & 97,34 & 2,66 \\
10 & $\begin{array}{l}\text { Aquades + } \\
\text { tanah 0,9 gr }\end{array}$ & 318,94 & 318,94 & 318,94 & 331,4 & 96,24 & 3,76 \\
\hline
\end{tabular}

Berdasarkan data akurasi dan kesalahan pada Tabel 4, kekeruhan dengan penambahan pengotor tanah 0,1 gr memiliki tingkat akurasi terkecil, yaitu $85,47 \%$. Sampel tersebut memiliki persen kesalahan yang lebih dari $10 \%$. Hal ini disebabkan oleh konsentrasi tanah yang sedikit, sehingga kecepatan pengendapan partikel lebih besar. Kecepatan pengendapan partikel yang besar menyebabkan zat pengotor, yaitu tanah mengendap ke bawah sehingga cahaya tidak terhalang oleh partikel dan intensitas cahaya cepat mengalami perubahan. Selain itu, partikel yang jumlahnya sedikit menyebabkan cahaya yang diteruskan menuju fototransistor kurang terhalangi dengan baik, sehingga persentase kesalahan yang diperoleh cukup besar. Pada air tanah memiliki batas pengukuran tegangan 0 NTU hingga 318,94 NTU dengan rata-rata akurasi sebesar 94,66\%. Hasil pengambilan data kekeruhan air abu dengan alat ukur buatan dapat dilihat pada Tabel 5.

Tabel 5. Data pengukuran alat ukur buatan (air abu)

\begin{tabular}{cccccccc}
\hline No & $\begin{array}{c}\text { Jenis } \\
\text { Sampel }\end{array}$ & $\begin{array}{c}\text { Pengukuran 1 } \\
\text { (NTU) }\end{array}$ & $\begin{array}{c}\text { Alat ukur buatan } \\
\text { Pengukuran 2 } \\
\text { (NTU) }\end{array}$ & $\begin{array}{c}\text { Pengukuran 3 } \\
\text { (NTU) }\end{array}$ & $\begin{array}{c}\text { Alat } \\
\text { standar } \\
\text { (NTU) }\end{array}$ & $\begin{array}{c}\text { Akurasi } \\
\text { (\%) }\end{array}$ & $\begin{array}{c}\text { Kesalahan } \\
\text { (\%) }\end{array}$ \\
\hline 1 & $\begin{array}{l}\text { Aquades } \\
\text { Murni }\end{array}$ & 0 & 0 & 0 & 0 & 100 & 0 \\
2 & $\begin{array}{l}\text { Aquades }+ \\
\text { abu 0,1 gr }\end{array}$ & 29,89 & 29,89 & 29,89 & 26,4 & 86,78 & 13,22 \\
3 & $\begin{array}{l}\text { Aquades }+ \\
\text { abu 0,2 gr }\end{array}$ & 67,33 & 67,33 & 67,33 & 71,94 & 93,59 & 6,41 \\
4 & $\begin{array}{l}\text { Aquades + } \\
\text { abu 0,3 gr }\end{array}$ & 104,33 & 104,33 & 104,33 & 106 & 98,42 & 1,58 \\
5 & $\begin{array}{l}\text { Aquades }+ \\
\text { abu 0,4 gr }\end{array}$ & 130,22 & 130,22 & 130,22 & 130,7 & 99,63 & 0,37 \\
6 & $\begin{array}{l}\text { Aquades + } \\
\text { abu 0,5 gr }\end{array}$ & 180,33 & 180,33 & 180,33 & 175,7 & 97,36 & 2,64 \\
7 & $\begin{array}{l}\text { Aquades + } \\
\text { abu 0,6 gr }\end{array}$ & 208,85 & 208,85 & 208,85 & 216 & 96,69 & 3,31 \\
8 & $\begin{array}{l}\text { Aquades }+ \\
\text { abu 0,7 gr }\end{array}$ & 243,77 & 244,65 & 244,65 & 235,2 & 96,11 & 3,89 \\
9 & $\begin{array}{l}\text { Aquades }+ \\
\text { abu 0,8 gr }\end{array}$ & 262 & 262,84 & 262 & 267,6 & 98,01 & 1,99 \\
10 & $\begin{array}{l}\text { Aquades + } \\
\text { abu 0,9 gr }\end{array}$ & 285,13 & 285,13 & 285,13 & 284,4 & 99,74 & 0,26 \\
\hline
\end{tabular}

Berdasarkan data akurasi dan kesalahan pada Tabel 5, kekeruhan dengan penambahan pengotor abu 0,1 gr memiliki tingkat akurasi terkecil, yaitu $86,78 \%$. Sampel tersebut memiliki persen kesalahan yang lebih dari $10 \%$. Hal ini disebabkan oleh konsentrasi abu yang sedikit, sehingga kecepatan pengendapan partikel lebih besar dikarenakan gaya gesek antar partikelnya kecil. Kecepatan pengendapan partikel yang besar menyebabkan bagian yang diukur tidak lagi terhalangi oleh partikel sehingga intensitas cahaya cepat mengalami perubahan. Pada air abu memiliki batas pengukuran tegangan 0 NTU hingga 285,13 NTU dengan rata-rata akurasi sebesar 96,63\% 
Suliyani N, Suciyati SW, Pauzi GA, dan Surtono A, 2021, Rancang Bangun Alat Ukur Kekeruhan Air Menggunakan Fototransistor dan LED Inframerah Berbasis Arduino Uno, Journal of Energy, Material, and Instrumentation Technology, Vol. 2 No. 2, 2021

\section{Kesimpulan}

Berdasarkan hasil penelitian dan analisis yang telah dilakukan diperoleh kesimpulan bahwa semakin tinggi tingkat kekeruhan air, maka semakin tinggi pula nilai tegangan yang diperoleh. Sensor fototransistor yang digunakan sangat peka terhadap cahaya, sehingga intensitas cahaya perlu dikurangi agar perubahan kekeruhan dapat terdeteksi. Hasil perbandingan alat ukur buatan dengan alat standar juga menunjukkan grafik trend linier, dimana semakin tinggi nilai tegangan pada alat buatan, maka semakin tinggi pula nilai kekeruhan yang diperoleh pada alat ukur standar. Alat ukur buatan memiliki batas pengukuran minimum 0 NTU dan maksimum 318,94 NTU untuk air tanah, sedangkan untuk air abu batas pengukuran minimum sebesar 0 NTU dan maksimum sebesar 285,13 NTU. Berdasarkan hasil pengukuran pada kedua sampel diperoleh tingkat akurasi sebesar 94,66\% untuk air tanah dan $96,63 \%$ untuk air abu.

\section{Ucapan Terimakasih}

Penulis mengucapkan terima kasih kepada PT. Sari Segar Husada yang telah membantu dalam menyelesaikan penelitian ini.

\section{Daftar Pustaka}

Artanto, D. (2012). Aplikasi Mikrokontroler ATMega8535 dan ATMega16. Yogyakarta: Andi.

Ebaay Search. (2013). Datasheet Micro SD Adapter.

Faisal, M., Harmadi, \& Puryanti, D. (2016). Perancangan Sistem Monitoring Tingkat Kekeruhan Air secara Realtime Menggunakan Sensor TSD-10. Jurnal Ilmu Fisika, 8(1), 9-16.

Fraden, J. (2003). Handbook of Modern Sensors (Physic, Design, and Applications) (Third Edition). New York: Springer International Publishing.

Hendrizon, Y., \& Wildian. (2012). Rancang Bangun Alat Ukur Tingkat Kekeruhan Zat Cair Berbasis Mikrokontroller AT89S51 Menggunakan Sensor Fototransistor dan Penampil LCD. Jurnal Fisika Unand, 1(1), 6-11.

Ikhsan, M. A., Yahya, M., \& Fiolana, F. A. (2018). Pendeteksi Kekeruhan Air di Tandon Rumah Berbasis Arduino Uno. Jurnal Que Teknika, 8(2), 17-29.

Joko, T. (2010). Unit Air Baku dalam Sistem Penyediaan Air Minum (Pertama). Yogyakarta: Graha Ilmu.

Kadir, A. (2013). Panduan Praktis Mempelajari Aplikasi Mikrokontroler dan Pemrogramannya Menggunakan Arduino. Yogyakarta: Andi.

Kautsar, M., Isnanto, R. R., \& Widianto, E. D. (2015). Sistem Monitoring Digital Penggunaan dan Kualitas Kekeruhan Air PDAM Berbasis Mikrokontroler ATMega328 Menggunakan Sensor Aliran Air dan Sensor Fotodiode. Jurnal Teknologi Dan Sistem Komputer, 3(1), 79-86.

Khoswanto, H. (2003). Odometer Digital untuk Kendaraan dengan Mikrokontroler MCS51. Jurnal Teknik Mesin, $6(1), 75-82$

Maemunnur, A. F., Wiranto, G., \& Waslaluddin. (2016). rancang Bangun Alat Ukur Turbidity Untuk Analisis Kualitas Air Berbasis Arduino Uno. 4(1), 2-9.

Mantech Electronics. (2017). Datasheet LCD I2C. Mantech Electronics (Pty) Ltd.

Mazidi, M. A. (2011). The Microcontroller and Embedded System: Using Assembly and C. New Jersey: Pearson Education, inc.

Nuzula, N. I., \& Endarko. (2013). Rancang Bangun Alat Ukur Kekeruhan Air Berbasis Mikrokontroler. Jurnal Berkala Fisika, 16(4), 111-118.

Rohman, A. (2007). Kimia Farmasi Analisis. Yogyakarta: Pustaka Pelajar.

Rukaesih, A. (2004). Kimia Lingkungan. Yogyakarta: Andi.

Silalahi, J. (2010). Analisis Kualitas Air dan hubungannya dengan Keanekaragaman Vegetasi Akuatik di Perairan Alige Danau Toba. Tesis. Universitas Sumatera Utara.

Sutrisno, C. T. (2004). Teknologi Penyediaan Air Bersih. Jakarta: Rineka Cipta.

Yusfi, M., Wildian, \& Hedlyni. (2011). Pemanfaatan Sensor Fototransistor Dan Led Inframerah dalam Pendeteksi Kekeruhan Air Berbasis Mikrokontroler AT89S51. Jurnal Ilmu Fisika, 3(2), 80-85.

Zamri, A. (2017). Desain Alat Pendeteksi Kekeruhan Air Minum di Bak Sedimentasi Pada Instalasi Pengolahan Air (IPA) PDAM “Way Rilau” Kota Bandar Lampung. Skripsi. Universitas Lampung. 